\title{
Treatment selection of early stage non- small cell lung cancer: the role of the patient in clinical decision making
}

\author{
S. Mokhles ${ }^{1 *}$, J. J. M. E. Nuyttens², M. de Mol${ }^{4}$, J. G. J. V. Aerts ${ }^{3,4}$, A. P. W. M. Maat ${ }^{1}$, Ö. Birim ${ }^{1}$, A. J. J. C. Bogers ${ }^{1}$ \\ and J. J. M. Takkenberg ${ }^{1}$
}

\begin{abstract}
Background: The objective of this study is to investigate the role and experience of early stage non-small cell lung cancer (NSCLC) patient in decision making process concerning treatment selection in the current clinical practice.

Methods: Stage I-II NSCLC patients (surgery 55 patients, SBRT 29 patients, median age 68) were included in this prospective study and completed a questionnaire that explored: (1) perceived patient knowledge of the advantages and disadvantages of the treatment options, (2) experience with current clinical decision making, and (3) the information that the patient reported to have received from their treating physician. This was assessed by multiple-choice, 1-5 Likert Scale, and open questions. The Decisional Conflict Scale was used to assess the decisional conflict. Health related quality of life (HRQoL) was measured with SF-36 questionnaire.

Results: In 19\% of patients, there was self-reported perceived lack of knowledge about the advantages and disadvantages of the treatment options. Seventy-four percent of patients felt that they were sufficiently involved in decision-making by their physician, and $81 \%$ found it important to be involved in decision making. Forty percent experienced decisional conflict, and one-in-five patients to such an extent that it made them feel unsure about the decision. Subscores with regard to feeling uninformed and on uncertainty, contributed the most to decisional conflict, as $36 \%$ felt uninformed and $17 \%$ of patients were not satisfied with their decision. HRQoL was not influenced by patient experience with decision-making or patient preferences for shared decision making.

Conclusions: Dutch early-stage NSCLC patients find it important to be involved in treatment decision making. Yet a substantial proportion experiences decisional conflict and feels uninformed. Better patient information and/or involvement in treatment-decision-making is needed in order to improve patient knowledge and hopefully reduce decisional conflict.
\end{abstract}

Keywords: Cancer patients, Decision-making preferences, Shared decision-making, Surgery, Radiation oncology

\section{Background}

Surgical resection is considered the preferred treatment for patients with early-stage non-small cell lung cancer (NSCLC). A less invasive option for patients with comorbidities is stereotactic body radiotherapy (SBRT) $[1,2]$. Several studies have demonstrated that SBRT may be as effective as surgery in potentially operable patients, however, randomized trials with larger patient populations and

\footnotetext{
*Correspondence: s.mokhles@erasmusmc.nl

'Department of Cardio-thoracic Surgery, Erasmus-MC, Room Bd-577, P.O. Box 2040, 3000 CA Rotterdam, The Netherlands

Full list of author information is available at the end of the article
}

longer follow-up are still lacking [3-5]. In this setting it is important to provide adequate information to allow patients to take an active role in treatment decision.

Shared decision making (SDM) is a process in which physician and patient work together in making a health decision after discussing the options, the benefits and harms, and considering the patients' values, preferences, and circumstances [6, 7]. SDM is seen as the middle ground between informed choice, where the patient makes the decision based on information received from the physician, and traditional paternalistic decision making, where the physician makes the decision based on best available 
evidence $[8,9]$. Patients who are active participants in the process of their care, for example asking questions, expressing their opinions and preferences, have better health outcomes, more knowledge regarding the disease and they are less anxious than patients who do not participate in the decision making [7, 10-12]. SDM supports patient to understand the disease and weigh advantages and disadvantages of treatment options in their own context, which will result in an informed treatment decision making with patients' needs and values incorporated. Although SDM has gained increased awareness among the healthcare community, it has not been widely incorporated into routine clinical practice in lung cancer care. This can be explained by the fact that there is lack of familiarity with SDM [13, 14], and also because the care of lung cancer patient can be complex due to multiple treatment types over an extended period of time and often includes a guideline-drive treatment [15]. Furthermore, there are a number of factors that complicate the implementation of SDM in current clinical practice such as guideline based treatments, patient knowledge, time constrains and care settings $[16,17]$.

This study assesses among Dutch early-stage NSCLC patients: (1) perceived patient knowledge of the advantages and disadvantages of treatment options, (2) experience with current clinical decision-making, and (3) perceived understanding of information regarding their disease and the treatment.

\section{Methods}

\section{Patient population}

Between December 2012 and December 2014, 155 consecutive patients with stage I or II NSCLC were recruited for this prospective observational study. These patients were subsequently treated surgically or with SBRT at Erasmus University Medical Center, Erasmus MC-Cancer Institute, or Amphia Hospital Breda. Consecutive patients were contacted by telephone to explain the purpose of the study and obtain their consent to receive a questionnaire. Only patients who agreed to participate and provided written informed consent were eligible for the inclusion in this study $(n=84)$. The overall response rate was $54 \%$. No significant differences were found between responders and non-responders in terms of baseline characteristics. This study was approved by the institutional review board of Erasmus University Medical Center (MEC 2012-462).

Clinical staging of patients treated surgically $(n=55)$ or with SBRT $(n=29)$ was done with CT-scan, ${ }^{18}$ FDG-PET imaging and/or using (minimally invasive) endoscopic techniques when appropriate. Clinical and pathological staging was based on American-Joint-Committee-in-Cancer 7thedition staging manual [18]. Chronic obstructive pulmonary disease (COPD) was defined according to the GOLD criteria [19]. Comorbidity-scores were recorded using the Charlson-Comorbidity-Index (CCI) [20]. Treatment planning of patients who received SBRT have been described previously [21]. All patients were discussed in a multidisciplinary team meeting before being accepted for treatment.

\section{Data collection}

Baseline characteristics of patients were collected by reviewing the patients' medical records and hospital information system. After the treatment decision was made but before the actual start of the treatment, patients completed a questionnaire. The aim of this questionnaire is to investigate: (1) perceived patient knowledge of the advantages and disadvantages of treatment options, (2) experience with current clinical decision-making (this includes the preferences, patient experience and involvement in treatment decision-making using Decisional Conflict Scale (DCS) and Control Preferences Scale (CPS), and (3) perceived understanding of information regarding their disease and the treatment. These components are measured at baseline using multiple-choice questions, a 1-5 Likert Scale, and open questions. Health-related-quality-of-life (HRQoL) was measured before the treatment, 6 months and 12 months after the treatment using the Short-Form 36-Item Health Survey (SF-36). For details regarding the questionnaire see Additional file 1.

\section{Control preference scale}

The patients' preferred decisional role was assessed using a modified version of the CPS. The CPS is an instrument that assesses preferences regarding patient participation in health care decisions. Patients were asked to select one of the five statements on roles in treatment decision-making; (A) the physician makes the decision about the treatment alone, (B) the physician makes the decision after considering the patient's opinion, $(\mathrm{C})$ the patient makes the decision together with the clinician, (D) the patient makes the decision after considering the doctor's opinion, and (E) the patient makes the decision about the treatment alone [22-24]. This scale has been widely used in previous studies $[25,26]$. To investigate the potential association between education level and CPS patients were asked to indicate their educational attainment.

\section{Decisional conflict scale}

The DCS was used to assess the level of 'decisional conflict' that patients experience while making health care decisions. This scale has been extensively validated and has been widely used. The DCS measures decision uncertainty that leads to decision delay, and quantifies modifiable factors which contribute to uncertainty. It contains 16 items, each using a five-point Likert response format (i.e. completely agree, agree, neither agree nor disagree, disagree, completely disagree). These items are combined to form total score 
and five subscales (i.e. uncertainty, informed, values clarity, support, and effective decision subscore). Scores lower than 25 are associated with implementing decisions and scores exceeding 37.5 are associated with delay or feeling unsure about implementation $[27,28]$. In case of missing values $(<6 \%)$ we used a multiple imputation technique to impute missing values in order to avoid them being depicted as 'unknown' in incomplete observations. We have used 5fold multiple imputation using SPSS for Windows version 21 [29]. In the surgery group 32 and 19 patients were alive at 6 and 12 months without tumor progression, respectively. In the SBRT group this was 9 and 4 patients at 6 and 12 months, respectively. Due to the low response rates at 6 and 12 months we could not explore decisional conflict over time.

\section{Health related quality of life assessment}

HRQoL was measured with the SF-36. The SF-36 is the most extensively used and evaluated health outcomes measure and has shown to be valid and reliable in multiple populations. The SF-36 assess eight self-reported aspects of HRQoL (i.e. physical functioning, role physical functioning, role emotional functioning, mental health, vitality, social functioning, bodily pain, and general health). It also yields physical (PCS) and mental (MCS) health summary measures. Scale scores are obtained by summing the items together within a domain, dividing this outcome by the range of scores and then transforming the scores to a scale from 0 to 100 [30]. The mean score of the PCS and MCS is 50 with a standard deviation of 10 and wherein a higher score means a better health status. Furthermore, a higher score on the SF-36 subdomains represents a better functioning; a high score on the bodily pain scale indicates the absence of pain. The scale has good reliability, with Cronbach $\alpha$ ranging from 0.65 to 0.96 for all subscales [31]. We used the Dutch adaptation of the SF-36 health status scale [32]. Patients were asked to complete the SF-36 form after treatment decision was made but before the treatment (baseline), at 6 and 12 months to all surviving patients. In case of missing values we applied simple imputation [33, 34]. HRQoL was assessed in 84 patients at baseline (surgery $=55$, SBRT $=29$ ). Due to the low response rates at 6 and 12 months (surgery group 32 and 19 patients were alive at 6 and 12 months and this was in the SBRT group 9 and 4 patients, respectively) the effect of time could not be analyzed.

Local control and the presence of metastases were defined according to the guidelines of ACCP and STS [35]. Twelve patients were diagnosed with tumor recurrence after the treatment, four of these patients had both locoregional and distant recurrence.

\section{Statistical analysis}

Continuous data are reported as mean $\pm \mathrm{SD}$ or median with range, and categorical data are reported as proportions. Normally distributed continuous variables were compared by using Student $t$ tests, and not normally distributed (Kolmogorov-Smirnov) data were compared by using the Mann-Whitney-U-test. Discrete variables were compared by using the Chi-Square test or the Fisher Exact test where appropriate. Aim 1 and 3 of this manuscript were analyzed using simple statistics by counting the 'yes' and 'no' answers. Components measured with 1-5 Likert-scale were not categorized.

A general linear model (GLM) with the bootstrap method was used to assess the association between HRQoL measured at baseline and 1) patient experience with involvement in treatment selection, 2) patient preferences for SDM, and 3) patients' preferred decisional role in treatment decision-making (assessed with CPS). The purpose behind the use of bootstrapping is to account for skewed distribution of residuals of SF-36 variables $[36,37]$ and to obtain valid and reliable $p$-values.

All statistical tests were two-tailed and a $p$-value of $<0.05$ was regarded as statistical significant. The statistical software package SPSS for Windows version 21 (SPSS Inc., Chicago, IL) was used for data analysis. GraphPad Prism5.00 for Windows (GraphPad software, San Diego, CA) was used to obtain graphs of QoL.

\section{Results}

The baseline characteristics of all 84 patients are listed in Table 1. In 55 patients surgical treatment was chosen (median age $=65$ ), in 29 patients SBRT (median age = 73). In this cohort of patients the education level was in accordance with the education level of the general Dutch population [38].

\section{Perceived patient knowledge regarding the treatment}

Self- reported lack of knowledge about the advantages and disadvantages of the treatment options was present in $18 \%$ of patients in the surgery group and in $22 \%$ of patients in the SBRT group. Self-reported lack of knowledge about the treatment risks was present in $6 \%$ of patients in the surgery group and in $21 \%$ of patients in the SBRT group.

\section{Experience with current clinical decision-making Patient preferences for SDM}

The majority (85\%) of patients agreed that ideally decision-making should be done together with the physician. Twelve percent of patients wanted to leave the decision about the appropriate treatment to their treating physician and 3\% indicated that the decision should be done mainly by patients. No association was found between the education level and the control preference scale. 
Table 1 Patient characteristics

\begin{tabular}{|c|c|c|c|c|}
\hline Characteristics & Total $(n=84)$ & Surgery $(n=55)$ & Radiotherapy $(n=29)$ & $P$-value \\
\hline Sex & & & & 0.406 \\
\hline -Male (\%) & $44(52)$ & $27(49)$ & $17(59)$ & \\
\hline -Female (\%) & $40(48)$ & $28(51)$ & $12(41)$ & \\
\hline Age, median (range) & $68(50-87)$ & $65(50-81)$ & $73(52-87)$ & 0.001 \\
\hline Education level (\%): & & & & 0.875 \\
\hline -Primary education & $12(14)$ & $8(15)$ & $4(14)$ & \\
\hline -Secondary education & $21(55)$ & $29(53)$ & $17(59)$ & \\
\hline -Higher education & $46(27)$ & $15(27)$ & $8(27)$ & \\
\hline -Other & $3(4)$ & $3(5)$ & - & \\
\hline \multicolumn{5}{|l|}{ Smoking habits } \\
\hline -Nonsmoker (\%) & $3(4)$ & $2(4)$ & $1(3)$ & 0.588 \\
\hline -Current or former smoker (\%) & $60(71)$ & $38(69)$ & $22(76)$ & \\
\hline -Unknown, n (\%) & $21(25)$ & $15(27)$ & $6(21)$ & \\
\hline $\mathrm{FEV}_{1} \%$ mean $\pm \mathrm{SD}^{\mathrm{a}}$ & $80(24)$ & $87(20)$ & $67(26)$ & 0.001 \\
\hline -Unknown, n (\%) & $3(4)$ & $2(4)$ & $1(3)$ & \\
\hline $\mathrm{DLCO}(\%)$ mean $\pm \mathrm{SD}^{\mathrm{b}}$ & $76(24)$ & $83(22)$ & $61(22)$ & $<0.001$ \\
\hline COPD $(\%)^{c}$ & & & & 0.001 \\
\hline -No COPD & $38(45)$ & $31(56)$ & $7(24)$ & \\
\hline -GOLD I & $17(20)$ & $10(18)$ & $7(24)$ & \\
\hline -GOLD ॥ & $19(23)$ & $13(24)$ & $6(21)$ & \\
\hline$-G O L D \| I$ & $8(10)$ & $1(2)$ & $7(24)$ & \\
\hline -GOLD IV & $2(2)$ & - & $2(7)$ & \\
\hline Charlson comorbidity index (\%) & & & & 0.026 \\
\hline$-\leq 1$ & $47(56)$ & $33(60)$ & $14(48)$ & \\
\hline$-2-3$ & $26(31)$ & $17(31)$ & $9(32)$ & \\
\hline-4 & $6(7)$ & $3(5)$ & $3(10)$ & \\
\hline$-\geq 5$ & $5(6)$ & $2(4)$ & $3(10)$ & \\
\hline Clinical stage (\%) & & & & 0.001 \\
\hline$-\mid A$ & $47(56)$ & $22(40)$ & $25(86)$ & \\
\hline$-\mid \mathrm{B}$ & $14(17)$ & $12(22)$ & $2(7)$ & \\
\hline$-\| A$ & $17(20)$ & $15(27)$ & $2(7)$ & \\
\hline$-\| B$ & $6(7)$ & $6(11)$ & & \\
\hline \multicolumn{5}{|l|}{ Pathological stage (\%) } \\
\hline$-\mid A$ & $17(31)$ & $17(31)$ & - & \\
\hline$-\mid \mathrm{B}$ & $18(33)$ & $18(33)$ & - & \\
\hline$-\| A$ & $9(16)$ & $9(16)$ & - & \\
\hline$-\| B$ & $7(13)$ & $7(13)$ & - & \\
\hline$-\| I \mid A / B$ & $4(7)$ & $4(7)$ & - & \\
\hline Histology (\%) & & & & 0.262 \\
\hline -Squamous cell carcinoma & $18(21)$ & $14(26)$ & $4(14)$ & \\
\hline -Adenocarcinoma & $21(25)$ & $15(27)$ & $6(21)$ & \\
\hline -Large cell carcinoma & $8(10)$ & $6(11)$ & $2(7)$ & \\
\hline$-N S C L C$ & $37(44)$ & $20(36)$ & $17(58)$ & \\
\hline
\end{tabular}


Table 1 Patient characteristics (Continued)

\begin{tabular}{|c|c|c|c|c|}
\hline Characteristics & Total $(n=84)$ & Surgery $(n=55)$ & Radiotherapy $(n=29)$ & P-value \\
\hline Clinical tumor diameter (mm), median (range) & $25(7-130)$ & $29(7-130)$ & $22(9-41)$ & $<0.001$ \\
\hline -Unknown, n (\%) & & $11(5)$ & - & \\
\hline Pathological tumor diameter (mm), median (range) & $28(1-90)$ & $28(1-90)$ & - & \\
\hline
\end{tabular}

${ }^{\mathrm{a}} \mathrm{FEV}_{1} \%$ : Forced expiratory volume in $1 \mathrm{~s}$ expressed as a percent of predicted

${ }^{b}$ Diffusion capacity of the lung for carbon monoxide

${ }^{c} \mathrm{COPD}$ : chronic obstructive pulmonary disease

\section{Experience in treatment decision-making}

On average, patients in this cohort discussed their treatment with three physicians. The majority of patients in the surgery and SBRT group involved a family member in making the choice for a treatment, 75 and 68\%, respectively. Most of patients thought that they had enough time to make an informed decision (80\% in the surgery group and $79 \%$ in the SBRT group). Patients indicated that several subjects were discussed during the conversation with their treating physician. Two percent of patients in the surgery group had the feeling that not every aspect of the treatment was discussed during the conversation with their treating physician. This was $11 \%$ in the SBRT group.

In the surgery group, $40 \%$ of patients experienced decisional conflict (score $>25$ ), and $22 \%$ to such an extent that they felt unsure about their decision (score > 37.5). Thirty-two percent felt uncertain about the best choice, and 39\% felt uninformed. Twenty-nine percent felt unclear about personal values for benefits and side effects of the treatment. Twenty-one percent felt unsupported in decision-making, and $21 \%$ of patients were not satisfied with their decision.

In the SBRT group, $48 \%$ of patients experienced decisional conflict, and $7 \%$ to such an extent that they felt unsure about their decision. Thirty-five percent felt uncertain about the best choice, and 29\% felt uninformed. Thirty-two percent felt unclear about personal values for benefits and side effects of the treatment. Fourteen percent felt unsupported in decision-making, and $7 \%$ of patients were not satisfied with their decision. Subscores on feeling uninformed and on uncertainty contributed the most to decisional conflict. Scores exceeding 37.5 are described here, details of the total score and five subscales for the two treatment groups are illustrated in Fig. 1.

\section{Involvement in treatment decision-making}

Seventy-four percent of patients felt that they were sufficiently involved in decision-making by their physician, $73 \%$ felt that they had a choice between different treatment options, $81 \%$ found it important to be involved in decision-making, $6 \%$ reported that alternative treatment options and complementary treatments were not discussed during the conversation about their treatment.
Patients mentioned immunotherapy, diet and vitamin supplements as an example. Involvement in treatment decision-making for the two treatment groups can be found in Table 2.

\section{Perceived understanding of information regarding the disease and the treatment}

Patients were asked to report which topics were discussed during the conversation about their treatment. Figure 2 illustrates that the minority of patients who undergone surgery or radiation therapy received information about the survival, 24 and $18 \%$, respectively.

\section{Health related quality of life assessment}

At baseline, patients in the surgery group scored higher on physical component summary (mean $42.4 \pm 12.3$ ) than patients in the SBRT group (mean 34.4 \pm 10.1 ), Fig. 3. No major differences could be found between the HRQoL in the surgery and SBRT group for the other measured SF-36 scales, except for physical functioning and general health (Fig. 4). Recurrence rates and death rates are illustrated in Table 3.

\section{SDM and HRQoL at baseline}

No significant association could be found between HRQoL and patient experience with involvement in treatment selection $(\mathrm{PCS} p$-value $=0.398, \operatorname{MCS} p$-value $=0.341$ ), patient preferences for SDM (PCS $p$-values $=$ 0.439 , MCS $p$-value $=0.580)$, and final decision in lung cancer treatment selection $(\mathrm{PCS} p$-value $=0.402, \mathrm{MCS}$ $p$-value $=0.662)$.

\section{Discussion}

This study illustrate that in the current clinical practice lung cancer patients experience decisional conflict and suboptimal information provision regarding the treatment and survival which highlights the need of improvement of information conveyance, and involvement of patients with early-stage NSCLC in treatment decision-making.

\section{Perceived patient knowledge regarding the treatment and communication with the patient}

Up to one-fifth of patients reported lack of knowledge about the advantages and disadvantages of the 


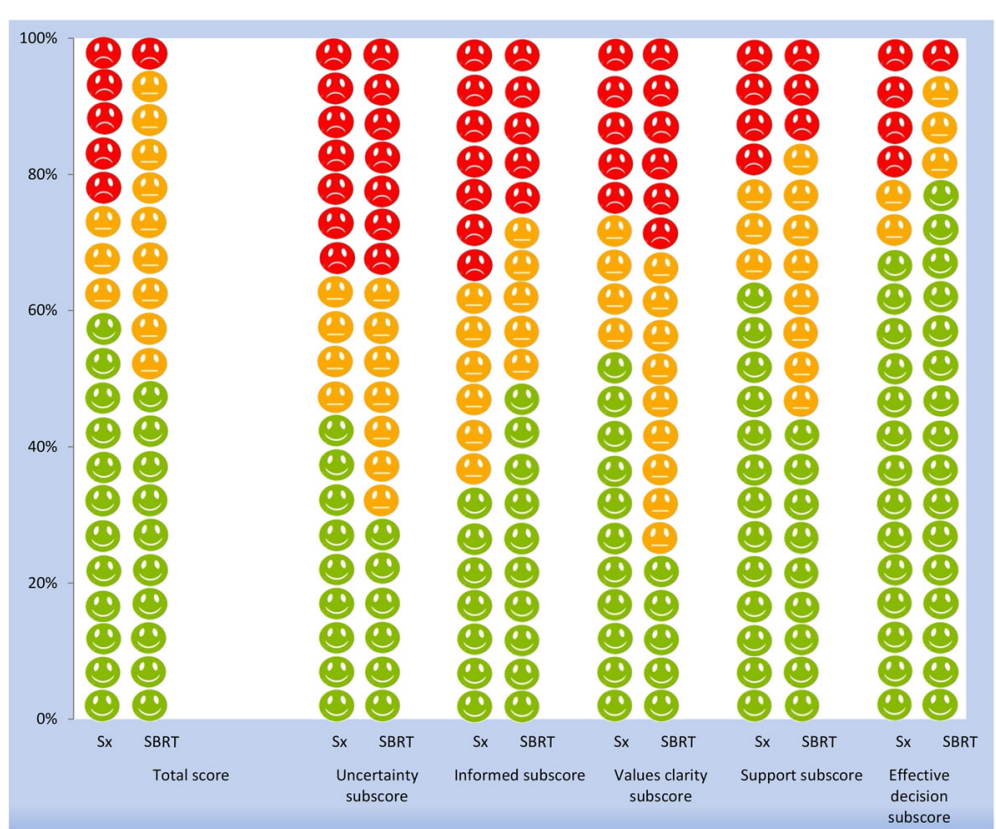

Fig. 1 Decisional conflict in patients treated surgically or with stereotactic body radiotherapy (SBRT). Scores $<25$ (green smiley) are associated with implementing decisions and scores $<37.5$ (red smiley) are associated with delay or feeling unsure about implementation. Orange smiley represent scores between 25 and 37.5

treatment options and one-tenth of patients reported lack of knowledge about the treatment risks. These results illustrate that providing information needs to improve, particularly in an early stage of diagnosis and treatment because lung cancer patients are emotionally unstable and could be overloaded with information about their disease [39]. Numerous studies explored different strategies to improve and adopt SDM in clinical practice [40]. One of the main topics of improving cancer communication is 'health literacy' which involves the ability of the patient to read, understand, and use health information to make an appropriate decision. In order to achieve an effective communication it is essential to describe health state in language that is accessible to the patient and discuss the benefits and risks of treatment options in a balanced way [41, 42]. In the field of breast cancer it is illustrated that by deciding on a cancer treatment without fully understanding the associated risks and benefits could lead to overuse or underuse of cancer treatments [43, 44].

Table 2 Involvement in treatment decision making for the two treatment groups

\begin{tabular}{lll}
\hline Involvement in decision making & Surgery (\%) & Radiotherapy (\%) \\
\hline - Felt sufficiently involved & 78 & 68 \\
- Found important to be involved & 78 & 89 \\
- Having a choice & 71 & 79 \\
- Not having a choice & 18 & 7 \\
\hline
\end{tabular}

Additionally, the majority of patients felt sufficiently involved in treatment decision-making and indicated that they had enough time to make an informed decision. It was interesting to see that the minority of patients reported to have received information on survival. It is crucial to discuss survival and prognosis with the patient in a way that the patient will understand this

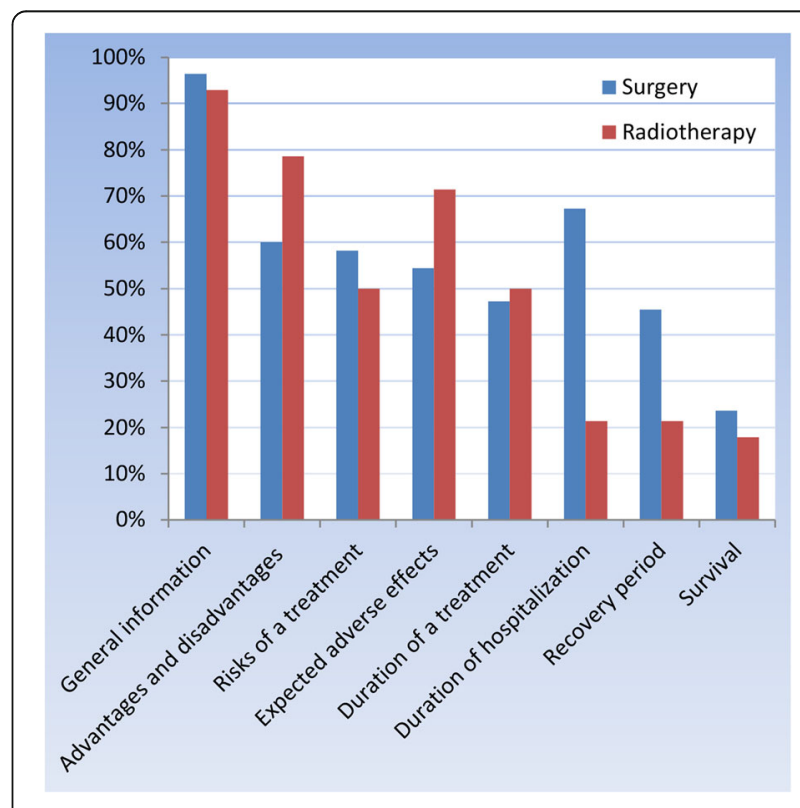

Fig. $\mathbf{2}$ Information that the patient received during the consultation 


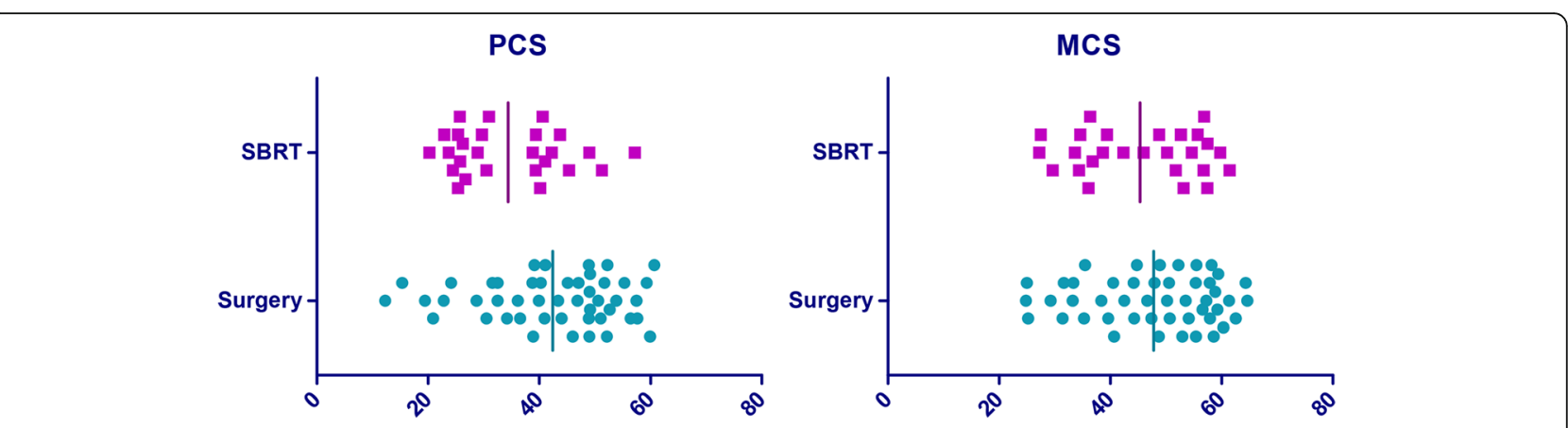

Fig. 3 Scatterplot of physical component summary (PCS) and mental component summary (MCS) at baseline in the surgery and stereotactic body radiotherapy (SBRT) group

information because previous studies have shown that the cancer patients overestimate their life expectancy and probabilities of cure when compared to their physicians' perspective [45-47]. This will lead to unrealistic high expectations about the medical treatment which is a common phenomenon in oncology patients $[48,49]$.

\section{Experience with current clinical decision-making}

The majority of patients had a strong desire to participate in treatment decision-making and preferred the decision to be the outcome of a SDM-process. This is in line with the previous studies showing that more patients preferred to participate rather than delegate decisions [50]. One of the challenges of SDM is knowing how much involvement a patient wants and needs. It is even more difficult when patients vary in the amount of control that they prefer to have over the treatment decision-making at the time of diagnosis [26]. Using tools such as decision aids prior to the consultation or during the visit will improve the communication between the patient and physician and there will be more

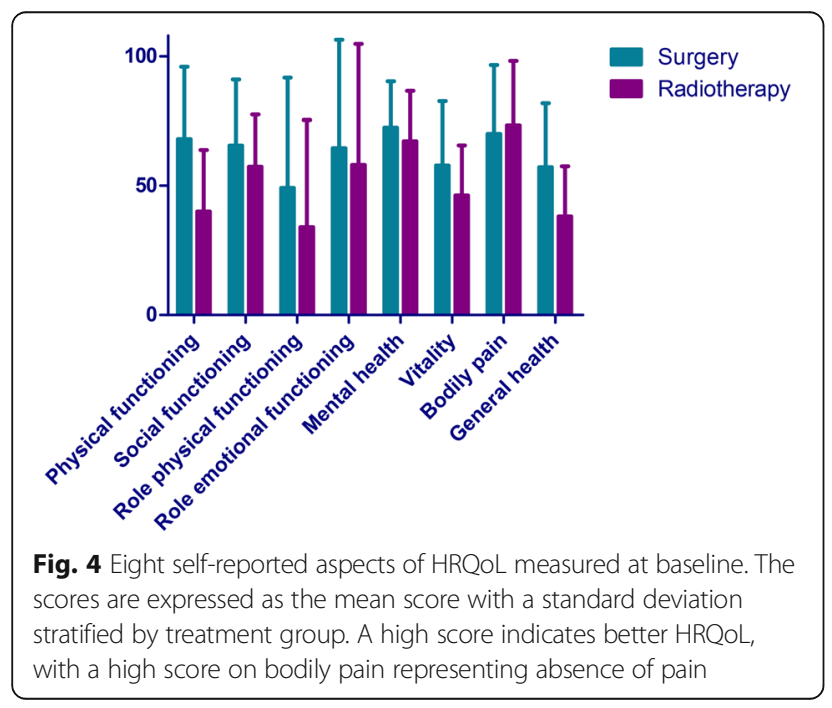

time for the patient to absorb health care information and ask questions during the consultation [51, 52].

Forty percent of patients experienced decisional conflict, and one in five patients to such an extent that it made them feel unsure about the decision. Decisional conflict was most evident in the uncertainty and informed subscale, suggesting that improvement of patient uncertainty and better informing the patient before the treatment will improve the quality of decision-making [27]. The same rates has been reported by patients treated for other type of cancer [53, 54]. Various factors can play a role in high levels of decisional conflict in cancer patients. First, most cancer patients want as much information as possible, however, they could be overloaded with information when it is offered 'all at once' or when the information is not provided to the patients' family [55]. As we have illustrated in this study, an inadequate level of perceived information contributes the most to decisional conflict. Second, periodic assessment of cancer patient's information requirements is also crucial, considering the complexity of cancer care. Finally, in our previous study we have illustrated that patients who receive SBRT differ significantly from the surgical patients [56]. It is important to appreciate these differences and realize that SBRT patients do not always have a choice between treatment options.

Table 3 Recurrence rate of patients treated surgically or with SBRT. Four patients had both loco-regional recurrence and distant recurrence

\begin{tabular}{lll}
\hline & Surgery (\%) & Radiotherapy (\%) \\
\hline All recurrence & $9(16)$ & $3(10)$ \\
Time till all & $1.1 \pm 0.7$ months & $0.4 \pm 0.06$ months \\
recurrence(mean \pm SD) & & \\
Local recurrence & $1(2)$ & - \\
Loco-regional recurrence & $4(7)$ & $1(3)$ \\
Distant recurrence & $9(16)$ & $2(7)$ \\
Death & $5(9)$ & $8(28)$ \\
\hline
\end{tabular}


Although decisional conflict is about what patients go through when confronted with a difficult decision, the idea of decisional conflict is also to help patients to think about participation in decision-making and motivate them to engage in treatment decision-making [57]. Furthermore, these scales also illustrate how patients are informed and where the improvements are needed.

\section{Health related quality of life and shared decision making}

In general, lung cancer patients have poor HRQoL compared to the general population or patients without lung cancer $[58,59]$. In this study, patients in the SBRT group scored at baseline lower on physical component summary compared to patients treated surgically. No differences could be found regarding the mental component summary. An explanation for the observed differences in HRQoL between the two groups could be the significant differences in baseline characteristics $[2,56]$. No association could be found between HRQoL and different aspect of SDM meaning that in this study HRQoL was not positively or negatively influenced by patient experiences with SDM. Our findings are comparable with a number of studies concluding that there is weak evidence that aspects of SDM are positively or negatively associated with QoL outcomes [60].

\section{Strengths and limitations}

The present study is a prospective observational cohort study allowing for new insights into the process of SDM and information conveyance in lung cancer patients. Although many articles have been written on SDM and patient participation in treatment decision-making in cancer patients, to our knowledge little research has been done on the role of early-stage lung cancer patients -treated surgically or with SBRT- in treatment decisionmaking and patients experiences and preferences regarding SDM. Also, the lung cancer patients were surveyed after diagnosis but before the treatment which allow us to investigate the unbiased perception of the patient regarding the treatment decision-making.

Potential limitations need to be addressed regarding the present study. First, the conceptual design of this study was not built on a specific theory. We explicitly chose to include all patients with stage I or II NSCLC who were planned for a surgical treatment or SBRT. We wanted to illustrate the patient participation in treatment decision-making, since there is little research about the role of early-stage lung cancer patients -treated surgically or with SBRT- in treatment decisionmaking. Second, overall response rate was 54\% thus making the sample size of this study small. The nonresponders were contacted to ask why they would not be part of the study. The following major reasons were given: 1) they were shocked by the diagnosis and therefore they did not want to complete the questionnaire; 2) they were too preoccupied with their illness and therefore they had no time for the questionnaire; 3) the questionnaire was too confrontational. However, no significant differences were found between responders and non-responders in terms of baseline characteristics. Third, we are aware of the shortcomings of using GLM. By using the bootstrap method we have tried to account for this inadequacy. However, no differences were observed between the results of GLM and results of GLM with bootstrapping. Finally, the response rate at 6 and 12 months was low due to recurrences rates and death rates in both treatment groups making analyses of HRQoL at 6 and 12 months difficult.

\section{Conclusions}

Shared-decision-making (SDM), where patients are involved as active partners with the physician in treatment decisions, is an important part of patientcentered cancer care as it weighs the pros and cons of treatment options while taking patients values and preferences into account.

Dutch early-stage NSCLC patients find it important to be involved in treatment decision-making. The majority of patients in this study found it important to be involved in decision-making and reported that they felt sufficiently involved by their treating physician. Yet a substantial proportion of patients experiences decisional conflict and feels uninformed. HRQoL was not influenced by patient experiences with SDM. Better patient information, and patient involvement in treatment decision-making is needed in order to improve patient knowledge and hopefully reduce decisional conflict.

\section{Additional file}

Additional file 1: Questionnaire used in the study. Description of data: Questionnaire used in the study. (DOC 50 kb)

\section{Abbreviations \\ ACCP: American College of Chest Physicians; CCl: Charlson-Comorbidity- Index; COPD: Chronic obstructive pulmonary disease; CPS: Control Preferences Scale; DCS: Decisional Conflict Scale; GLM: General linear model; HRQOL: Health related quality of life; MCS: Mental component summary; NSCLC: Non-small cell lung cancer; PCS: Physical component summary; SBRT: Stereotactic body radiotherapy; SDM: Shared-decision-making; SF- 36: Short-Form 36-Item Health Survey; STS: Society of Thoracic Surgeons}

\section{Acknowledgments}

The authors thank Laixi Xue for her support in data collection.

\section{Funding}

This work had no specific funding and there are no financial disclosures from any authors.

Availability of data and materials

The raw data is available upon request from the corresponding author. 


\section{Authors' contributions}

The idea for this paper originated from the conjoined experience of $S M, J N$, JA, MdeM, AM, OB, HT and AB. All authors conceived and designed the questionnaire including correcting the questionnaire at different stages of the design. JN, JA, MdeM, AM, OB recruited actively patients from clinical practice. SM did the statistical analysis and wrote the paper together with HT and $A B$. SM, JT and AB revised the work critically for important intellectua content. All authors were responsible for the final approval of this paper ensuring that questions related to the accuracy or integrity of any part of the work are appropriately investigated and resolved. All authors read and approved the manuscript.

\section{Ethics approval and consent to participate}

This study was approved by the institutional review board of Erasmus University Medical Center (MEC 2012-462). Only patients who agreed to participate and provided written informed consent were eligible for the inclusion in this study. Consent regarding publication of individual patient data was waived by Ethics committee of Erasmus MC

\section{Consent for publication}

Not applicable.

\section{Competing interests}

The authors declare that they have no competing interests.

\section{Publisher's Note}

Springer Nature remains neutral with regard to jurisdictional claims in published maps and institutional affiliations.

\section{Author details}

'Department of Cardio-thoracic Surgery, Erasmus-MC, Room Bd-577, P.O. Box 2040, 3000 CA Rotterdam, The Netherlands. ${ }^{2}$ Department of Radiation Oncology, Erasmus-MC-Cancer Institute, Rotterdam, The Netherlands. ${ }^{3}$ Department of Pulmonary Disease, Erasmus-MC, Rotterdam, The Netherlands. ${ }^{4}$ Department of Pulmonary Disease, Amphia Hospital, Breda, The Netherlands.

Received: 7 July 2016 Accepted: 2 January 2018

Published online: 15 January 2018

\section{References}

1. Vansteenkiste J, Crino L, Dooms C, Douillard JY, Faivre-Finn C, Lim E, Rocco G, Senan S, Van Schil P, Veronesi G, et al. 2nd ESMO Consensus Conference on Lung Cancer: early-stage non-small-cell lung cancer consensus on diagnosis, treatment and follow-up. Ann Oncol. 2014;25(8):1462-74.

2. Mokhles S, Verstegen N, Maat AP, Birim O, Bogers AJ, Mokhles MM, Lagerwaard FJ, Senan S, Takkenberg JJ. Comparison of clinical outcome of stage I nonsmall cell lung cancer treated surgically or with stereotactic radiotherapy: results from propensity score analysis. Lung Cancer. 2015;87(3):283-9.

3. Chang JY, Senan S, Paul MA, Mehran RJ, Louie AV, Balter P, Groen HJM, McRae SE, Widder J, Feng L, et al. Stereotactic ablative radiotherapy versus lobectomy for operable stage I non-small-cell lung cancer: a pooled analysis of two randomised trials. Lancet Oncol. 2015;16(6):630-7.

4. Solda F, Lodge M, Ashley S, Whitington A, Goldstraw P, Brada M. Stereotactic radiotherapy (SABR) for the treatment of primary non-small cell lung cancer; systematic review and comparison with a surgical cohort Radiother Oncol. 2013:109(1):1-7.

5. Treasure T, Rintoul RC, Macbeth F. SABR in early operable lung cancer: time for evidence. Lancet Oncol. 2015;16(6):597-8.

6. Elwyn G, Frosch D, Thomson R, Joseph-Williams N, Lloyd A, Kinnersley P, Cording E, Tomson D, Dodd C, Rollnick S, et al. Shared decision making: a model for clinical practice. J Gen Intern Med. 2012;27(10):1361-7.

7. Oshima Lee E, Emanuel EJ. Shared decision making to improve care and reduce costs. N Engl J Med. 2013;368(1):6-8.

8. Emanuel EJ, Emanuel LL. Four models of the physician-patient relationship. JAMA. 1992:267(16):2221-6.

9. Jordan JL, Ellis SJ, Chambers R. Defining shared decision making and concordance: are they one and the same? Postgrad Med J. 2002; 78(921):383-4
10. Fowler FJ Jr, Gallagher PM, Drake KM, Sepucha KR. Decision dissonance: evaluating an approach to measuring the quality of surgical decision making. Jt Comm J Qual Patient Saf. 2013;39(3):136-44.

11. Ryan J, Sysko J. The contingency of patient preferences for involvement in health decision making. Health Care Manag Rev. 2007;32(1):30-6.

12. Murray E, Pollack L, White M, Lo B. Clinical decision-making: Patients' preferences and experiences. Patient Educ Couns. 2007;65(2):189-96.

13. Gravel K, Legare F, Graham ID. Barriers and facilitators to implementing shared decision-making in clinical practice: a systematic review of health professionals' perceptions. Implement Sci. 2006;1:16.

14. Friedberg MW, Van Busum $K$, Wexler R, Bowen M, Schneider EC. A demonstration of shared decision making in primary care highlights barriers to adoption and potential remedies. Health Aff (Millwood). 2013:32(2):268-75.

15. Hoffmann TC, Montori VM, Del Mar C. The connection between evidencebased medicine and shared decision making. JAMA. 2014:312(13):1295-6.

16. Joseph-Williams N, Elwyn G, Edwards A. Knowledge is not power for patients: a systematic review and thematic synthesis of patient-reported barriers and facilitators to shared decision making. Patient Educ Couns. 2014:94(3):291-309.

17. Mokhles S, Maat A, Aerts J, Nuyttens J, Bogers A, Takkenberg JJM. Opinions of lung cancer clinicians on shared decision making in early-stage non-small-cell lung cancerdagger. Interact Cardiovasc Thorac Surg. 2017;25:278-84.

18. Goldstraw P. IASLC staging manual in thoracic oncology. 1st ed. Orange Park: Editorial Rx Press; 2009

19. Rabe KF, Hurd S, Anzueto A, Barnes PJ, Buist SA, Calverley P, Fukuchi Y, Jenkins C, Rodriguez-Roisin R, van Weel C, et al. Global strategy for the diagnosis, management, and prevention of chronic obstructive pulmonary disease: GOLD executive summary. Am J Respir Crit Care Med. 2007;176(6):532-55.

20. Charlson ME, Pompei P, Ales KL, Mackenzie CR. A new method of classifying prognostic comorbidity in longitudinal studies: development and validation. J Chronic Dis. 1987:40(5):373-83.

21. Nuyttens JJ, van de Pol M. The CyberKnife radiosurgery system for lung cancer. Expert Rev Med Devices. 2012:9(5):465-75.

22. Degner LF, Sloan JA, Venkatesh P. The control preferences scale. Can J Nurs Res. 1997:29(3):21-43.

23. Salkeld G, Solomon M, Short L, Butow PN. A matter of trust-patient's views on decision-making in colorectal cancer. Health Expect. 2004;7(2):104-14.

24. Janz NK, Wren PA, Copeland LA, Lowery JC, Goldfarb SL, Wilkins EG. Patientphysician concordance: preferences, perceptions, and factors influencing the breast cancer surgical decision. J Clin Oncol. 2004;22(15):3091-8.

25. Wallberg B, Michelson H, Nystedt M, Bolund C, Degner LF, Wilking N. Information needs and preferences for participation in treatment decisions among Swedish breast cancer patients. Acta Oncol. 2000;39(4):467-76.

26. Mallinger JB, Shields CG, Griggs JJ, Roscoe JA, Morrow GR, Rosenbluth RJ, Lord RS, Gross H. Stability of decisional role preference over the course of cancer therapy. Psychooncology. 2006;15(4):297-305.

27. O'Connor AM. Validation of a decisional conflict scale. Med Decis Mak. 1995; 15(1):25-30.

28. Koedoot N, Molenaar S, Oosterveld P, Bakker P, de Graeff A, Nooy M, Varekamp I, de Haes $\mathrm{H}$. The decisional conflict scale: further validation in two samples of Dutch oncology patients. Patient Educ Couns. 2001;45(3): 187-93.

29. Rubin DB. Multiple imputation for non-response in surveys. New York: Wiley; 1997.

30. Ware JE Jr, Sherbourne CD. The MOS 36-item short-form health survey (SF-36). . Conceptual framework and item selection. Med Care. 1992:30(6):473-83.

31. Smith HJ, Taylor R, Mitchell A. A comparison of four quality of life instruments in cardiac patients: SF-36, QLI, QLMI, and SEIQoL. Heart. 2000; 84(4):390-4.

32. Aaronson NK, Muller M, Cohen PD, Essink-Bot ML, Fekkes M, Sanderman R, Sprangers MA, te Velde A, Verrips E. Translation, validation, and norming of the Dutch language version of the SF-36 Health Survey in community and chronic disease populations. J Clin Epidemiol. 1998:51(11):1055-68.

33. Bandayrel $\mathrm{K}$, Johnston BC. Recent advances in patient and proxy-reported quality of life research. Health Qual Life Outcomes. 2014;12(1):110.

34. Coste J, Quinquis L, Audureau E, Pouchot J. Non response, incomplete and inconsistent responses to self-administered health-related quality of life measures in the general population: patterns, determinants and impact on the validity of estimates - a population-based study in France using the MOS SF-36. Health Qual Life Outcomes. 2013;11:44. 
35. Donington J, Ferguson M, Mazzone $P$, Handy J Jr, Schuchert M, Fernando $H$, Loo B Jr, Lanuti M, de Hoyos A, Detterbeck F, et al. American College of Chest Physicians and Society of Thoracic Surgeons consensus statement for evaluation and management for high-risk patients with stage I non-small cell lung cancer. Chest. 2012;142(6):1620-35.

36. Efron B. Better bootstrap confidence-intervals. J Am Stat Assoc. 1987;82(397): 171-85.

37. Efron B. An introduction to the bootstrap method. New York: Chapmann and Hall/CRC; 1993.

38. Dutch population better educated. https://www.cbs.nl/en-gb/news/2013/ 40/dutch-population-better-educated.

39. Jensen JD, Carcioppolo N, King AJ, Scherr CL, Jones CL, Niederdieppe J. The cancer information overload (CIO) scale: establishing predictive and discriminant validity. Patient Educ Couns. 2014;94(1):90-6.

40. Legare F, Ratte S, Stacey D, Kryworuchko J, Gravel K, Graham ID, Turcotte S. Interventions for improving the adoption of shared decision making by healthcare professionals. Cochrane Database Syst Rev. 2010;5:CD006732.

41. Katz SJ, Belkora J, Elwyn G. Shared decision making for treatment of cancer: challenges and opportunities. J Oncol Pract. 2014;10(3):206-8.

42. Thorne S, Oliffe JL, Stajduhar KI. Communicating shared decision-making: cancer patient perspectives. Patient Educ Couns. 2013:90(3):291-6.

43. Katz SJ, Hawley ST. From policy to patients and back: surgical treatment decision making for patients with breast cancer. Health Aff (Millwood). 2007;26(3):761-9.

44. Bickell NA, Weidmann J, Fei K, Lin JJ, Leventhal H. Underuse of breast cancer adjuvant treatment: patient knowledge, beliefs, and medical mistrust. J Clin Oncol. 2009;27(31):5160-7.

45. Mackillop WJ, Stewart WE, Ginsburg AD, Stewart SS. Cancer-patients perceptions of their disease and its treatment. Br J Cancer. 1988;58(3):355-8.

46. Weeks JC, Cook EF, O'Day SJ, Petersen LM, Wenger N, Reding D, Harrell FE, Kussin P, Dawson NV, Connors AF, et al. Relationship between cancer patients' predictions of prognosis and their treatment preferences. JAMA. 1998;279(21):1709-14.

47. Reuben DB, Naeim A. Perspectives, preferences, care practices, and outcomes in late-stage cancer patients: connecting the dots. J Clin Oncol. 2004:22(24):4869-71.

48. Weeks JC, Catalano PJ, Cronin A, Finkelman MD, Mack JW, Keating NL, Schrag D. Patients' expectations about effects of chemotherapy for advanced cancer. N Engl J Med. 2012;367(17):1616-25.

49. Rosenberg SM, Tracy MS, Meyer ME, Sepucha K, Gelber S, Hirshfield-Bartek J, Troyan S, Morrow M, Schapira L, Come SE, et al. Perceptions, knowledge, and satisfaction with contralateral prophylactic mastectomy among young women with breast cancer: a cross-sectional survey. Ann Intern Med. 2013; 159(6):373-81.

50. Chewning B, Bylund CL, Shah B, Arora NK, Gueguen JA, Makoul G. Patient preferences for shared decisions: a systematic review. Patient Educ Couns. 2012;86(1):9-18

51. O'Connor AM, Bennett CL, Stacey D, Barry M, Col NF, Eden KB, Entwistle VA, Fiset $\mathrm{V}$, Holmes-Rovner M, Khangura S, et al. Decision aids for people facing health treatment or screening decisions. Cochrane Database Syst Rev. 2009; 3:CD001431.

52. Elwyn G, O'Connor AM, Bennett C, Newcombe RG, Politi M, Durand MA, Drake E, Joseph-Williams N, Khangura S, Saarimaki A, et al. Assessing the quality of decision support technologies using the International Patient Decision Aid Standards instrument (IPDASi). PLoS One. 2009;4(3):e4705.

53. Sim JA, Shin JS, Park SM, Chang YJ, Shin A, Noh DY, Han W, Yang HK, Lee HJ, Kim YW, et al. Association between information provision and decisional conflict in cancer patients. Ann Oncol. 2015;26(9):1974-80.

54. Taylor BA, Hart RD, Rigby MH, Trites J, Taylor SM, Hong P. Decisional conflic in patients considering diagnostic thyroidectomy with indeterminate fine needle aspirate cytopathology. J Otolaryngol Head Neck Surg. 2016;45:16.

55. Hope S, Williams AE, Lunn D. Information provision to cancer patients: a practical example of identifying the need for changes in practice from the Dorset cancer Centre. Eur J Cancer Care (Engl). 2000;9(4):238-42.

56. Mokhles S, Nuyttens JJ, Maat AP, Birim O, Aerts JG, Bogers AJ, Takkenberg JJ. Survival and treatment of non-small cell lung cancer stage I-II treated surgically or with stereotactic body radiotherapy: patient and tumor-specific factors affect the prognosis. Ann Surg Oncol. 2015;22(1):316-23.

57. Janis IL. Decision making:a psycological analysis of conflict, choice, and commitment New York: Free Press; 1977.
58. Poghosyan H, Sheldon LK, Leveille SG, Cooley ME. Health-related quality of life after surgical treatment in patients with non-small cell lung cancer: a systematic review. Lung Cancer. 2013;81(1):11-26.

59. Myrdal G, Valtysdottir S, Lambe M, Stahle E. Quality of life following lung cancer surgery. Thorax. 2003;58(3):194-7.

60. Kashaf MS, McGill E. Does shared decision making in cancer treatment improve quality of life? A systematic literature review. Med Decis Mak. 2015; 35(8):1037-48.

\section{Submit your next manuscript to BioMed Central and we will help you at every step:}

- We accept pre-submission inquiries

- Our selector tool helps you to find the most relevant journal

- We provide round the clock customer support

- Convenient online submission

- Thorough peer review

- Inclusion in PubMed and all major indexing services

- Maximum visibility for your research

Submit your manuscript at www.biomedcentral.com/submit
) Biomed Central 